\title{
RESENHA - A profissionalização dos formadores de professores
}

\author{
ALTET, Marguerite; PERRENOUD, Phillipe; PAQUAY, Léopold e coloboradores. A \\ profissionalização dos formadores de professores. São Paulo: Artmed Editora S.A, 2003. \\ (Tradução do original francês "Formateurs d'enseignants: quelle professionnalisation? \\ Copyrigth by: De Boeck \& Larcier S. A., 2002, por Fátima Murad).
}

Carlos Eduardo Porto Villani carlosvillani@yahoo.com.br

Nesse texto, apresenta-se uma resenha crítica do livro “A profissionalização dos formadores de professores” de autoria de Marguerite Altet, Philippe Perrenoud, Léopold Paquay e colaboradores. No livro estão reunidos onze trabalhos de importantes especialistas originários de três países francófonos: Bélgica, França e Suíça. Os trabalhos surgiram como resultado da articulação das pesquisas empíricas e reflexões teóricas produzidas pelos autores, sobre as questões que envolvem a profissionalização, a identidade e o papel dos sujeitos responsáveis pela formação dos professores: os formadores de professores. Muitas dessas questões guardam similaridades com a situação dos formadores de professores de outros países, o que torna esta obra uma referência internacional para a área de educação.

No livro, os trabalhos estão organizados em três partes. Na primeira, "a formação contínua” (mais conhecida no Brasil como formação continuada), estão reunidos três trabalhos que investigam a profissionalização dos formadores de professores que atuam junto a professores já habilitados que lecionam no ensino fundamental e médio em diversos níveis de escolaridade.

O primeiro trabalho da primeira parte do livro, "Formadores de professores uma identidade balbuciante" de autoria da suíça Mireille Snoeckx, aborda as questões da constituição da identidade dos formadores de professores a partir da reconstrução da história de vida desses sujeitos. Snoeckx procurou evidenciar as diferentes manifestações que o processo de profissionalização desses sujeitos assumiu no decorrer dos últimos vinte anos em Genebra, para compreender melhor a identidade do formador de professores de hoje. Seu trabalho nos permite fazer uma série de analogias com a realidade dos formadores de professores brasileiros e é um convite instigante para professores e pesquisadores realizarem investigações com abordagens históricas e estudos comparativos entre o contexto da profissionalização dos formadores de professores dos países francófonos e do Brasil.

Em "Dispositivos de formação de formadores de professores: para qual profissionalização?”, o Francês Maurice Lamy apresenta uma reflexão teórica do pronto de vista de um especialista não-universitário sobre a constituição de um dispositivo de "formação de formadores de professores". O dispositivo é cuidadosamente analisado levando-se em consideração suas referências cronológicas, seus princípios de base e seus referenciais conceituais e metodológicos. Em suas conclusões, Lamy questiona a eficácia 
do dispositivo analisado e de outros dispositivos de formação. O autor nos alerta que, embora seja indispensável haver uma mediação para a formação dos formadores de professores, sua profissionalização é mais uma questão de postura e de atitude do que matéria de dispositivos e de ferramentas de formação. Nesse sentido, o texto sugere implicitamente a necessidade de estudos que investiguem a dimensão moral presente nos processos de formação de professores, assim como sua inclusão nos cursos de formação continuada.

Finalmente, o terceiro e último texto da primeira parte do livro, "Qual (quais) profissionalidade (s) dos formadores em formação contínua? Por um perfil poliidentitário” é de autoria de Marguerite Altet, uma pesquisadora francesa professora de ciências da educação da Universidade de Nantes. Nesse texto, Altet apoiou-se em uma pesquisa realizada por questionário a 117 formadores da MAFPEN $^{1}$ em 1997. A maior parte dos formadores da MAFPEN são professores experientes que dedicam um terço ou meio período de seu serviço às atividades de formação. As questões suscitadas, na situação investigada sobre a profissionalidade dos formadores de professores, justificam a escolha deste texto para o fechamento desta primeira parte do livro. A natureza do instrumento utilizado para a obtenção dos dados permitiu a Altet uma análise na qual ela mesclou os resultados quantitativos advindos dos questionários com a constituição da profissionalidade específica do formador de professor a partir do seu próprio discurso. A autora buscou identificar o tipo de formação seguida pelo professor que se tornou formador de professores para compreender o modo como se constitui sua profissionalização. Em suas conclusões, a autora delineia um quadro mais otimista quanto a uma possível constituição da profissionalização dos formadores de professores que, segundo ela, já se encontra no nível de um principio de profissionalização de formadores de professores, no sentido da evolução da profissionalidade, como testemunha o perfil poliidentitário circunscrito na pesquisa.

Na segunda parte do livro, “a formação inicial”, estão reunidos seis trabalhos que abordam as questões associadas à profissionalização dos formadores que atuam nos cursos de formação inicial de professores nos institutos universitários.

O primeiro trabalho desta segunda parte "Formadores no IUFM: um mundo heterogêneo" apóia-se na idéia de que a profissionalização dos formadores de professores deve ser vista como uma dinâmica em curso, cujo resultado é sempre incerto. Vincent Lang, um professor conferencista na Universidade de Nantes, na França, é quem assina este interessante trabalho que apresenta a evolução das profissionalidades dos formadores de professores dos Institutos Universitários de Formação Inicial (IUFM). Lang investigou a dinâmica de profissionalização dos formadores a partir do olhar que os formadores lançam sobre si mesmos, sobre seu ofício e sobre suas evoluções. Em suas conclusões, o autor agrupa seus resultados em três séries de observações que, segundo ele, servem de “conclusões provisórias”: 1 - Embora, à primeira vista, os formadores do IUFM possam parecer constituir um mundo relativamente homogêneo, este mundo é na verdade bastante heterogêneo. 2 - O grupo de formadores investigados: a) insere-se em uma dinâmica de profissionalização dos ofícios de ensino b) reivindica uma imagem de professores especialistas c) tenta profissionalizar a formação em seu conteúdo. 3 - A evolução das

\footnotetext{
${ }^{1}$ Mission Académique de Formation des Personnels de l’Éducation Nationale, criada em 1982 por Alain Savary e encarregada da formação contínua de todos os professores de cada academia; vinculada em 1982 a cada IUFM - Institut Universitaire de Formation des Maîtres.
} 
profissionalidades e das identidades dos formadores provém essencialmente de políticas de formação de professores.

O segundo e o terceiro trabalhos procuram evidenciar as especificidades da formação inicial de professores na Bélgica. No trabalho intitulado "A profissionalidade dos formadores de professores na Bélgica: um contexto, um dispositivo” Jacqueline Beckers, professora da universidade de Liège, expõe o contexto de formação no qual se inserem estes dois trabalhos, em um quadro-resumo sintético que facilita seu entendimento por leitores não-belgas. O quadro evidencia a persistência de um duplo sistema de formação de professores caracterizado por duas categorias de formadores: os especialistas-matéria também conhecidos como “didatas” e os psicopedagogos. O trabalho de Beckers está dividido em duas partes. Na primeira ela procura situar o contexto belga propriamente dito. Na segunda, a autora analisa e estabelece um olhar reflexivo sobre um dispositivo de profissionalização destinado aos psicopedagogos. O dispositivo constitui um módulo de formação obrigatória de 60 horas, inserido na licenciatura em ciências da educação da Universidade de Liège, articulado com base em um período de estágio de futuros professores do “ensino secundário inferior no segundo ano de formação”. As conclusões de Beckers incidem diretamente sobre recomendações para se melhorar a compreensão e o êxito do dispositivo analisado.

Já o trabalho de Léopold Paquay “Abordagem da construção da profissionalidade dos psicopedagogos formadores de futuros professores” investiga empiricamente um importante conjunto de questões associadas à profissionalização dos psicopedagogos. Segundo Paquay a formação inicial dos psicopedagogos (a licenciatura em psicopedagogia ou a licenciatura em ciências da educação) não os preparou necessariamente para todas as tarefas requeridas. Dessa forma, o conjunto de questionamentos levantados nesta pesquisa focaliza o desenvolvimento da capacidade desses sujeitos em fazer face às exigências profissionais reais em situação, ou seja, o desenvolvimento de sua profissionalidade. Em suas conclusões o autor destaca a corroboração de resultados de pesquisas anteriores sobre o desenvolvimento profissional que ocorre ao longo da carreira: os práticos desenvolvem suas competências pela experiência e pela reflexão sobre a experiência. A organização do artigo, a metodologia de investigação, e a forma de exposição dos resultados são muito interessantes, o que torna a leitura do artigo uma importante referência sobre como desenvolver uma pesquisa e produzir um relato consistente desta pesquisa.

No quarto trabalho, “Os formadores como vetor essencial na reforma dos sistemas de formação. Perfis de atores e vias de uma formação profissionalizante” Olivier Maradan, então diretor de projeto para a Escola de Altos Estudos Pedagógicos de Friburgo, apresenta um relato sobre um projeto de constituição de um dispositivo de formação de formadores de professores. Nesse trabalho o autor se abstém de analisar o dispositivo enquanto pesquisador, mas assume seu lugar como idealizador e militante de um projeto de "reforma da profissionalização dos formadores de professores” na Suíça nos proporcionando uma visão ampla do referido processo.

O quinto trabalho apóia-se em 15 anos de pesquisa sobre a identidade e o trabalho dos formadores de professores da França. Patrice Pelpel, um professor conferencista no IUFM de Créteil, analisa alguns elementos da identidade dos formadores de campo (os conselheiros pedagógicos) e os fatores que se interpuseram como obstáculo ao seu processo de profissionalização em “Qual profissionalização para os formadores de campo?”. Em suas conclusões Palpel constata que a formação de professores desenvolve-se de uma maneira relativamente incoerente em relação às mudanças associadas à profissionalização 
dos formadores observadas na França, e apresenta três fortes questionamentos que provavelmente aparecerão em futuras investigações sobre este tema que são: 1- Como formar professores profissionais com formadores amadores? 2- Como recusar o empirismo em matéria de formação e convocar os práticos em função de sua experiência? E, finalmente 3 - Como se pode anunciar episodicamente o interesse pela formação de professores sem se preocupar com as condições que a tornariam possível?

O último trabalho desta parte é de autoria de Nadine Faingold, uma professora conferencista no IUFM de Versailles. Em seu trabalho "professores-tutores: quais práticas qual identidade profissional?” a autora investiga os processos a serem privilegiados no âmbito de uma formação de formadores de professores. Os professores-tutores são todos os sujeitos que se enquadram no conjunto dos profissionais encarregados do acompanhamento individualizado da formação prática dos professores. Os papéis de tais profissionais podem ser comparados aos dos professores que, no Brasil, recebem os alunos de graduação, de licenciatura ou pedagogia, em suas classes e que são encarregados de acompanhá-los nos seus respectivos estágios. Uma diferença marcante destes formadores com relação ao contexto brasileiro é que alguns deles recebem um certificado de aptidão para a função de professores formadores, o que lhes permite manter uma prática de classe exercendo suas novas funções de formador durante um terço de seu tempo de serviço. Essa especificidade é investigada no trabalho de Faingold que identifica as dificuldades encontradas por esses professores-tutores (inexperientes) no momento de sua passagem a essa nova identidade profissional de formador de adultos, e a compara com um estudo sobre o modo de intervenção por um conselheiro pedagógico experiente. A metodologia utilizada para construir suas conclusões sobre as práticas e as identidades desses profissionais foi a da “entrevista de explicitação" que permite acessar as dimensões da vivência e da ação que não estão imediatamente presentes na consciência da pessoa.

Finalmente, a terceira e última parte do livro reúne os trabalhos de dois pesquisadores suíços que envolvem temas que são comuns às questões discutidas sobre a profissionalização dos formadores que atuam tanto na formação inicial quanto na formação continuada de professores. A terceira parte é denominada de “questões transversais" e é composta pelos trabalhos intitulados "A divisão do trabalho entre formadores de professores: desafios emergentes” do sociólogo Philippe Perrenoud e “A profissionalização: entre competência e reconhecimento social” de Guy Jobert.

Perrenoud reflete sobre os papeis que os formadores desempenham analisando a divisão do trabalho entre eles e os desafios emergentes que podem constituir um sinal de profissionalização dos formadores de professores. Em suas conclusões, o autor apresenta um paradoxo: Se por um lado os formadores se recusam a reconhecer sua identidade enquanto formadores de professores, por outro lado, atualmente, é inegável o reconhecimento da existência da sua função de formador de professores. Diante da problemática da profissionalização dos formadores de professores, o autor sugere que uma possível (e talvez única) saída fosse a aproximação do ensino e da formação. Para Perrenoud "A evolução da didática como organização de situações de aprendizagem vai nesse sentido, assim como todos os trabalhos de orientação construtivistas. Um dia talvez os professores orgulhem-se de ser antes de tudo formadores, especialistas em processos de transformação de um aprendiz. Mas hoje ainda há uma distância enorme entre essa perspectiva e a identidade predominante de professores do ensino médio e do ensino superior”. 
Jobert discute os significados atribuídos ao termo profissionalização concentrandose particularmente na sua associação como desenvolvimento da competência e como luta social. Ele utiliza as considerações realizadas para examinar três questões práticas: a) Os formadores de professores são atores importantes da profissionalização dos professores? b) Como os formadores de professores podem contribuir para o desenvolvimento das competências dos professores? c) Os formadores de professores podem esperar um avanço de seu reconhecimento profissional? Como resposta a estas questões, o autor destaca que a profissionalização dos formadores de professores depende da emergência de um grupo social, profissional de formadores, fato este que ainda se encontra distante da realidade exposta nos contextos investigados.

Além dos trabalhos agrupados nas três partes detalhadas acima, Altet, Paquay e Perrenoud apresentam um capítulo de introdução, onde são colocadas as questões centrais abordadas (1 - Existe uma profissionalidade específica dos formadores de professores? Qual é? Como é construída? e 2 - Observa-se um processo de profissionalização da função e até mesmo do ofício dos formadores dos professores? Quais são os indicadores disso?) e outro de conclusão, onde estas questões são sintetizadas em termos das idéias expostas nos 11 trabalhos do livro. Nesse capítulo de conclusão fica evidenciado a existência de uma profissionalidade dinâmica caracterizada por uma grande diversidade de tarefas e pela existência de perfis variados e heterogêneos de representações de identidade dos formadores de professores. Além disso, as competências em construção, específicas aos formadores de professores identificadas em vários artigos, e as descrições, por meio de quais procedimentos elas se constroem, são indicadores consistentes da profissionalização da função de formador de professor. Entretanto, os autores deixam claro que ainda resta um longo caminho a percorrer até a constituição de uma futura profissão de "formador de professor". 